\title{
The Exploration of Big Data Smart Campus Construction
}

\author{
Hanbing $\mathrm{Chu}^{1, \mathrm{a}^{*}}$ and Jianjing $\mathrm{MaO}^{2, \mathrm{~b}}$ \\ ${ }^{1}$ Information Engineering Institute, Zhengzhou University of Industrial Technology, Xinzheng, \\ 451150, China; \\ ${ }^{2}$ Information Engineering Institute, Zhengzhou University of Industrial Technology, Xinzheng, \\ 451150, China

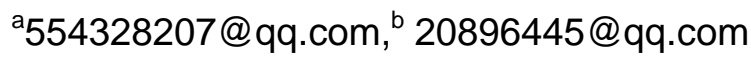 \\ * The Corresponding Author
}

Keywords: Smart campus; Big data; Construction; Data mining

\begin{abstract}
The advent of the big data era has promoted the improvement of the information level, while the construction of the smart campus of big data colleges and universities is still in the primary stage. This paper analyses the model of big data construction in Colleges and Universities, and further explains the important role of big data smart campus in teaching, scientific research, management, technical service, life service and other campus information, and puts forward a new model of building big data smart campus.
\end{abstract}

\section{Introduction}

With the introduction of big data, the growth of the data is faster than the bamboo shoots after the rain, and the decision-making in its related fields is no longer dependent on experience and consciousness. All according to the data analysis, it has also promoted the status of the data analysis industry, and the so-called "all speak with data ". So what is big data? In our opinion, big data is a process of obtaining valuable information table from data collection and analysis of data mining. Or big data exactly is a process.

The difference between big data and data is a big word. It can, $t$ reflect its large capacity, multiple types and quick access speed without "big" character. This is also the characteristics of university information such as university teaching, scientific research, management, technology service, life service and so on.

\section{The Problem of Big Data Construction in Domestic Universities}

At present, the information platform established by domestic universities usually establishes their own independent database and presentation layer according to the needs of each sub unit. So the software and the data standard is not uniform. The sub units form islands of information. Moreover, resource information data is difficult to share, which increases the difficulty of controlling data comprehensively. At the same time, it is difficult to analyze the data provided by information island, so as to obtain reliable decision-making basis. In the economy, it will cause the waste of school funds and repeated construction. At the school level, it will bring a lot of repetitive work to teaching, scientific research and management, resulting in low efficiency.

Colleges and universities generally pay attention to network construction and despise the construction of software platform. At present, all colleges and universities have almost popularized the backbone of the network, and realized the full network coverage of wired and wireless. However, without the establishment of a big data analysis platform the benefits of building a network can't be realized.

\section{Analysis of the Construction Mode of University Big Data Analysis Platform.}

The core of big data analysis platform is the sharing of data resources, which is the platform of integrated Internet of things and software platform. In terms of the construction mode, there are two 
types. The first mode is the overall plan, and the big data analysis platform is established according to the requirements of school teaching, learning, management, service and office. However, most colleges and universities have already established some information island platforms and applications, so it is difficult to redesign unified data standard and build new big data analysis platform. So we can only use the second mode. On the basis of the existing backbone network and the "information island" platform, unified planning and integration is carried out.

According to the survey, the establishment of big data in colleges and universities usually goes through three stages. The first stage is the construction of the traditional information campus. The second stage is the primary stage of digital campus, or smart campus. The third stage is called the big data campus or the digital campus and the smart campus stage. At present, most colleges and universities in China are in the second stage, which requires further integration of resources to realize the third stage.

The big data is to excavate and analyze mass data and obtain valuable information. At present, colleges and universities have a large number of user groups, as well as basic data acquisition system, as shown in Fig. 1.

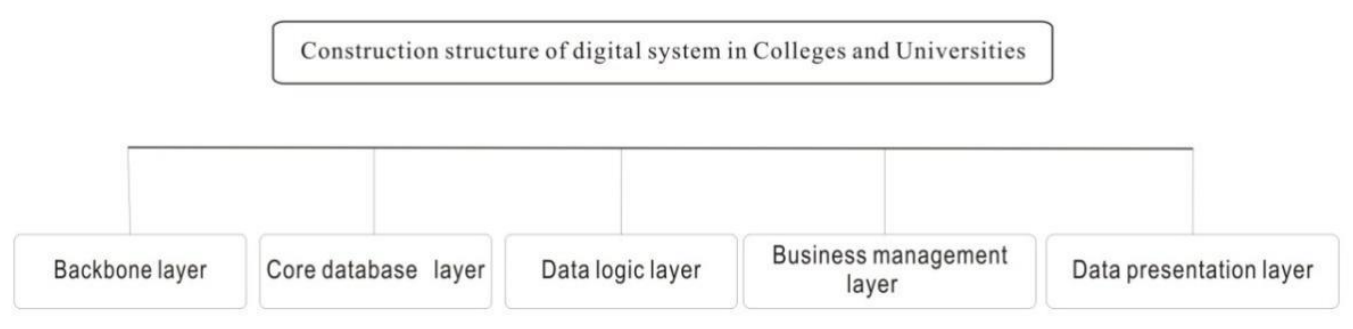

Figure 1. Finite basic structure of digital system in Colleges and Universities

For most colleges and universities, the current digital or intelligent campus system is based on the scale of figure 1. It is generally developed or integrated according to Model View Controller, that is, the model - view - controller framework system.

Only by integrating these levels can we improve the establishment of the big data platform of smart campus. The following is an analysis of the customized educational administration system, which should contain modules as shown in Fig. 2.

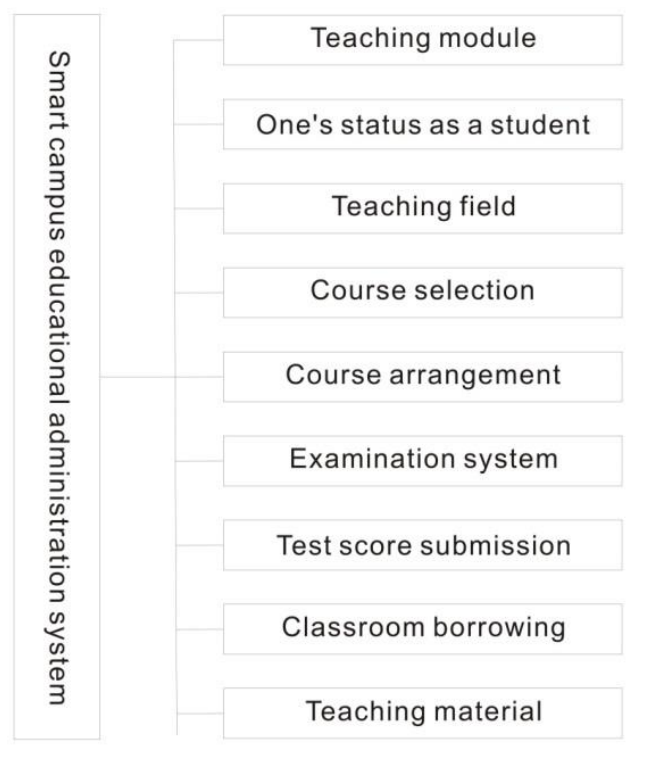

Figure 2. Finite Functional architecture of the educational administration system of smart campus 
It is not difficult to see from the above picture that the basic functions of teaching are basically covered, but the big data platform is different from the traditional teaching system architecture system. The teaching module is based on the classified data of personnel department in the core data layer. Based on the idea of data sharing and synchronization, the academic affairs office can call the human resource database at any time to analyze the teachers. Similarly, the student status module can be selected from the core database submitted by the admissions office, to master the number of students and to allocate the teaching resources reasonably, etc..

\section{Prospect of Big Data Smart Campus Platform}

Big data changes the concept of college and university teaching, and online learning will divide teachers into three categories directly. One type of teachers can get better development by providing high quality teaching resources. One type of teacher is called a teaching assistant to provide guidance and help for students. The last kind of teacher comes out from education and goes into scientific research to develop science better.

Furthermore, big data promotes personalized education. Online learning is not limited to space, time, and specialty. Students can develop their own learning plans according to their own learning situations and personal characteristics. According to their own knowledge reserve, learning ability and interest, students choose their own learning methods and learning skills, so that they can teach students in accordance with their aptitude.

The arrival of big data will lead to great changes in university teaching. Opportunities and challenges coexist. Big data smart campus is a major project to promote higher education in the whole university and even the whole country.

\section{Acknowledgements}

Fund Project: University-level scientific research project of Zhengzhou University of Industrial Technology.

Name: Research on big data construction in college and university

Project No. :2017YB008

\section{Reference}

[1] Luo Dan, Xu Hongyan, Zhang Yuhua.Design and implementation of smart campus in big data environment [J]. Computer and Modernization,2016(09):109-114.

[2] Du Wei. Research on the selection model of campus football players based on "big data" [D]. Qufu Normal University, 2016.

[3] Liu Minsi, Chen Shao bo. Research on the construction of smart campus in the era of big data [J]. Software Guide,2015,14(08):6-8.

[4] Wang Jun. Research on the innovation of information construction of college and university smart campus from the perspective of big data [J]. Computer and Telecommunications, 2015(05):83-87.

[5] Dong Bo, Zhang Yinling. A brief analysis of the smart campus [J]. Science and Technology Innovation, 2017 (35): 88-89.

[6] Zhang Dongxia, Miao Xin, Liu Liping, Zhang Yan, Liu Keyan. Research on the development of big data technology of smart power grid $[\mathrm{J}]$. Journal of Chinese electrical engineering,2015,35(01):2-12. 